\title{
Damage Monitoring of CP-GFRP/GFRP Composites by Measuring Electrical Resistance
}

\author{
Soon-Gi Shin ${ }^{\dagger}$ and Yong Jung Kwon* \\ Department of Advanced Materials Engineering, College of Samcheok, Kangwon National University, \\ Samcheok, Gangwon-do, 245-711, Republic of Korea \\ *Department of Chemical Engineering, College of Chuncheon, Kangwon National University, Chuncheon, \\ Gangwon-do, 200-701, Republic of Korea
}

(Received October 11, 2009 : Received in revised form March 12, 2010 : Accepted March 12, 2010)

\begin{abstract}
It is necessary to develop new methods to prevent catastrophic failure of structural material in order to avoid accidents and conserve natural and energy resources. Design of intelligent materials with a self-diagnosing function to prevent fatal fracture of structural materials was achieved by smart composites consisting of carbon fiber tows or carbon powders with a small value of ultimate elongation and glass fiber tows with a large value of ultimate elongation. The changes in electrical resistance of CF-GFRP/GFRP (carbon fiber and glass fiber-reinforced plastics/glass fiber-reinforced plastics) composites increased abruptly with increasing strain, and a tremendous change was seen at the transition point where carbon fiber tows were broken. Therefore, the composites were not to monitor damage from the early stage. On the other hand, the change in electrical resistance of CP-GFRP/GFRP (carbon powder dispersed in glass fiber-reinforced plastics/ glass fiber-reinforced plastics) composites increased almost linearly in proportion to strain. CP-GFRP/GFRP composites are superior to CF-GFRP/GFRP composites in terms of their capability to monitor damage by measuring change in electrical resistance from the early stage of damage. However, the former was inferior to the latter as an application because of the difficulties of mass production and high cost. A method based on monitoring damage by measuring changes in the electrical resistance of structural materials is promising for improved reliability of the material.
\end{abstract}

Key words carbon powder, plastics, electrical resistance, smart composites, damage monitoring.

\section{Introduction}

In the past the unforeseen sudden fracture of materials has caused many accidents and considerable damage. However most materials show some signs before fracture and most accidents could have been avoided if some sign of fracture initiation while the materials were still practically sound could be detected. A number of methods have been developed for detecting fracture, ${ }^{1-6)}$ but a usable method for detecting damage has not yet been developed. Until recently, policies to assure reliability had been either making the structures thicker and heavier or tougher and stronger. These policies resulted in the usage of a lot of resources during production and once the products are no longer used recycling becomes difficult with a lot of waste. Strain and dial gauges are used as general measuring methods for deformation and fracture of materials. ${ }^{6}$ In the case of large specimens, it is hard to obtain agreement between the fracture and the measuring position, and the use of numerous gauges results in false

Corresponding author

E-Mail : ssg@kangwon.ac.kr (S. -G. Shin) alarms as well as high cost. Non-destructive methods such as the acoustic emission method or the ultrasonic detection method are generally expensive, and require special operating te-chniques and analyses. ${ }^{1,2)}$ These sorts of cost and sophisticated methods are not practical for conventional structures. A general method for preventing accidental failure needs to be technically simple and cheap. Therefore, it is necessary to develop new methods for preventing catastrophic failure in order to prevent accidents and conserve natural and energy resources.

Materials themselves possess a self-diagnosing function for fracture; thus, strong and heavy design, complex and expensive equipment and numerous sensors become unnecessary. The necessity of materials with a selfdiagnosing function applied to structural materials needs a signal to indicate development of fracture before a fatal fracture takes place. Schulte has reported that measuring changes in electrical resistance of carbon fiber reinforced plastics (CFRP) composites during tensile and fatigue loading can be used as a non-destructive evaluation technique. ${ }^{7)}$ Muto has reported that a method based on monitoring changes in electrical resistance of CF-GFRP (carbon fiber and glass fiber reinforced plastics) com- 
posites during loading and residual electrical resistance afterwards is a promising technique for preventing fatal fractures by self-diagnosis., ${ }^{8,9}$

CF-GFRP composites were also tested as the reinforcement of concrete. The behavior of the loads and the change in electrical resistance of CF-GFRP reinforced concrete was similar to that measured for CF-GFRP composites containing the same kind of carbon fiber tows. ${ }^{10,11)}$ The changes in electrical resistance of CFGFRP reinforced concrete during loading and unloading increased linearly with the increase of load, strain and deflection. When applied load exceed the previous maximum load, the increase of the change in electrical resistance became non-linear. This phenomenon is useful since it helps to know the maximum value of the previous load by monitoring the change of electrical resistance during loading and unloading. Furthermore, by using two- and three-dimensional grid-like large CF-GFRP composites electrically independent from each other at the crossing positions, information on the location of damage can be obtained for concrete structural parts of the large scale. Therefore, CF-GFRP reinforced concrete can be used as intelligent materials for monitoring the condition of concrete structures in a variety of location, including underwater and underground applications, walls of atomic piles and other areas where visual inspection or access is difficult.

As an application of smart composites with intelligent function, the detection of water leakage and the measurement of water content in concrete materials were investigated with CF-GFRP composites used as a function of reinforced material and electrodes. ${ }^{12)}$ The water content in weight percent of concrete could be calculated from electrical conductivity measured using the cross section of CF-GFRP composites as electrodes, and the values of electrical resistance and electrical conductivity of concrete with cross section of CF-GFRP composites were affected by frequency, applied voltage and temperature. Also, the conductivity of cement mortar decreased with decreasing water content and the conductivity of cement mortar and concrete increased in short time with adsorbing or flowing water. Therefore, CF-GFRP composites are promising reinforcements for intelligent concrete structural materials capable of detecting both water content in weight percent and leakage of water.

However, a method based on monitoring damage by measuring changes in electrical resistance of CF-GFRP composites is necessary to produce fracture of carbon fiber tows during loading so that the method is not able to detect damage from the early stage of damage for structural materials before carbon fiber tows fracture.

The purpose of this study is to assess the capability of damage monitoring by measuring change in electrical resistance from the early stage of damage by comparing the carbon fiber tows with graphite powders used as the sensor material.

\section{Experimental Procedure}

In this study, smart composites containing conductive material with a small value of ultimate elongation and insulating fiber tows with a large value of ultimate elongation were tested as a specimen. Conductive material, conductive fiber tows with conductive powders were as follows. PAN-HMCT: polyacrylonitrile-based high modulus carbon fiber tows (Toho Rayon Co. Ltd, Japan: BESFIGHT; UM63) and carbon powders (graphite) with average particle size of $5 \mu \mathrm{m}$ (SEC Co. Ltd, Japan: SGP-5) were used as the conductive fiber tows and the conductive powders, respectively. The typical composition of the carbon powders measured by JIS M8812 method was (in wt. \%): fixed carbon 99.73, volatile material 0.22 , ash 0.05 , and sulfur $<0.01$, respectively. Also, the specific gravity was 2.242 . As the insulating fiber tows, inexpensive E-glass fiber tows (Asahi Fiber Glass Co. Ltd, Japan: ER2220) were chosen. This is because they can maintain loads even after the fracture of conductive materials. And they also have larger ultimate elongation and smaller longitudinal modulus than conductive materials and cost less. As the matrix, vinyl ester (Showa High Polymer Co. Ltd, Japan: RIPOXY R-804) was selected because of its superiority in alkali resistance for concrete. Table 1 shows the properties of raw materials used for CP-GFRP/GFRP (carbon powder in glass fiber reinforced plastics/glass fiber-reinforced plastics) composites and CF-GFRP composites. It was not necessary to compensate for temperate changes during and after loading, because the carbon fiber tows have low electri-

Table 1. Properties of a raw materials used for composites.

\begin{tabular}{ccccccc}
\hline Materials & $\begin{array}{c}\text { Tensile strength } \\
(\mathrm{MPa})\end{array}$ & $\begin{array}{c}\text { Elastic } \\
\text { modulus }(\mathrm{GPa})\end{array}$ & $\begin{array}{c}\text { Elongation } \\
(\%)\end{array}$ & $\begin{array}{c}\text { Particle size } \\
(\mu \mathrm{m})\end{array}$ & $\begin{array}{c}\text { Diameter } \\
(\mu \mathrm{m})\end{array}$ & $\begin{array}{c}\text { Number of } \\
\text { filament }\end{array}$ \\
\hline Carbon powder & - & - & - & 5 & - & - \\
Carbon fiber & 3530 & 610 & 0.6 & - & 4.3 & 12000 \\
Glass fiber & 3430 & 72.5 & 4.8 & - & 16 & 4200 \\
Vinyl ester & 79.4 & 3.23 & 4.6 & - & - \\
\hline
\end{tabular}




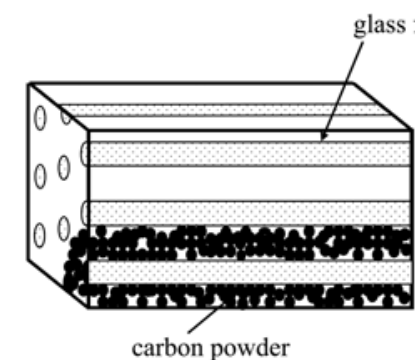

(a)

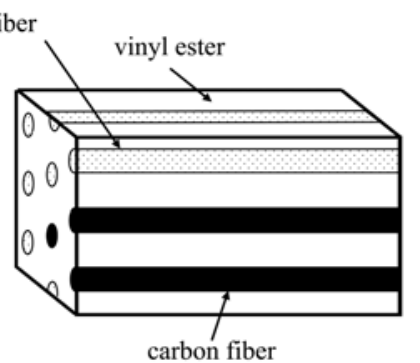

(b)
Fig. 1. Schematic drawing of (a) CP-GFRP/GFRP and (b) CF-GFRP/ GFRP composites.

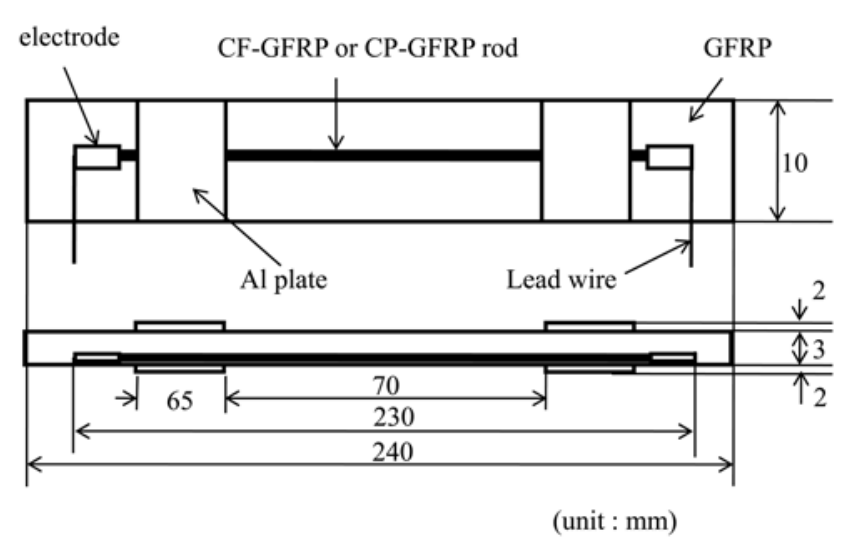

Fig. 2. Schematic drawing of the dimensions and the configuration in CF-GFRP/GFRP or CP-GFRP/GFRP composites.

cal resistance $(700 \mu \Omega \cdot \mathrm{cm})$ and are well graphitized as conductive fiber tows.

To fabricate electrically conductive CP-GFRP, the slurry containing carbon powder with vinyl ester resin was prepared. Various dispersion agents were checked chemically, and styrene monomer was the most effective as the dispersion agents for the slurry of carbon powder with vinyl ester. The slurry was prepared by mixing vinyl ester of $36 \%$ volume fraction as matrix, carbon powder of $10 \%$ volume fraction as the electrically conductive material for monitoring damage and styrene monomer of $54 \%$ volume fraction as the dispersion agents of slurry, respectively.

A tow of GF (glass fiber) filaments was immersed into the slurry stirred by ultrasonic vibration in order to fabricate the GF tows immersed in the high density slurry. The GF tow immersed fully in the slurry was pulled up continuously from inside the slurry, and filtered afterwards. Filtering was done by pulling through the small diameter wire-loop. This process was necessary to fabricate the CP-GFRP rod with low electrical resistance and high density. CP-GFRP rod was dried spontaneously and cut to necessary length.

As test specimens, CF-GFRP/GFRP and CP-GFRP/ GFRP composites were used, respectively. CF-GFRP/

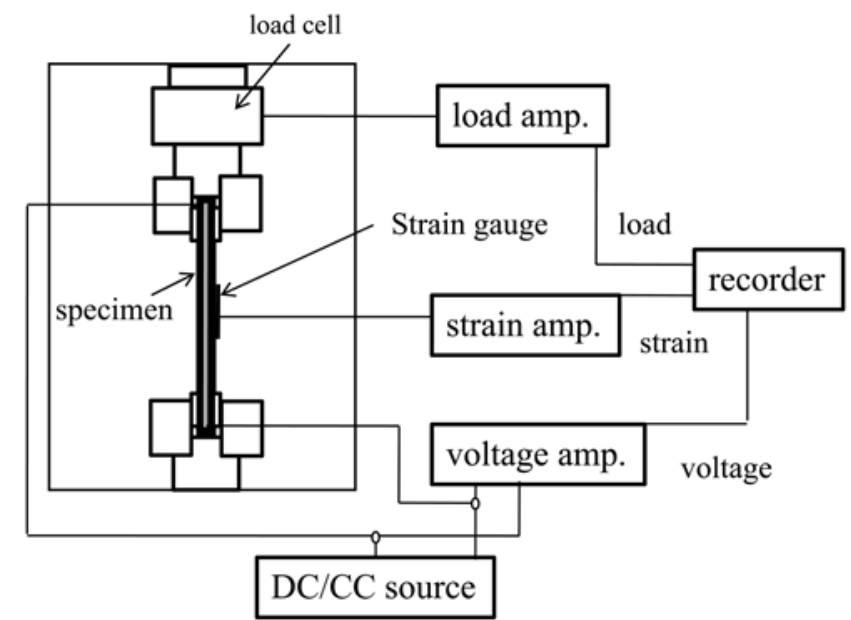

Fig. 3. Schematic drawing of the tension test.

GFRP was fabricated easily by the hand-lay-up method as a conventional fabrication method. ${ }^{13)}$ However, it was necessary to fabricate CP-GFRP/GFRP by a special technique. ${ }^{14)}$ The carbon fiber introduced for replacement of a part of glass fiber forms a conductive path and enhances strength in the long direction of composites. Fig. 1 shows the schematic drawing of CP-GFRP/GFRP and CF-GFRP/GFRP composites. The prepreg of GFRP composites was fabricated by the hand-lay-up method. The prepreg of cylindrical CP-GFRP rod consisting of only one number fabricated by the method mentioned in the preceding paragraph was inserted axially in the same direction as that of GF in GFRP composites as aligning into the center position of cross section of the test specimen. These electrically conductive materials were necessary to be continuous in order to monitor the change in electrical resistance between both ends of a specimen.

Fig. 2 shows the schematic drawing of the dimensions and the configuration of the specimen. The size of the specimen was $30 \mathrm{~mm}^{2}(3 \times 10 \mathrm{~mm})$ in cross-sectional area and $240 \mathrm{~mm}$ in length. Copper electrodes were attached to both ends of the specimen with silver paste so that the electrical resistance of the contact between these electrodes and the carbon fiber tows could be neglected. Further, Al plates were used as tagged metals in order to stop damage between the specimen and the grip of the tensile tester. The size of the Al plate were $20 \mathrm{~mm}^{2}(2 \times 10 \mathrm{~mm})$ in cross-sectional area and $65 \mathrm{~mm}$ in length, and they were bonded $20 \mathrm{~mm}$ inside from both ends of each specimen.

Fig. 3 shows the schematic drawing of the tension test. In order to examine changes in electrical resistance, the tensile test was conducted using a Tensilon-typed tensile tester (Shimadzu Co. Ltd, Japan, Auto Graph: AG-25TB) with a cross-head speed of $0.2 \mathrm{~mm} / \mathrm{min}$. The changes in 

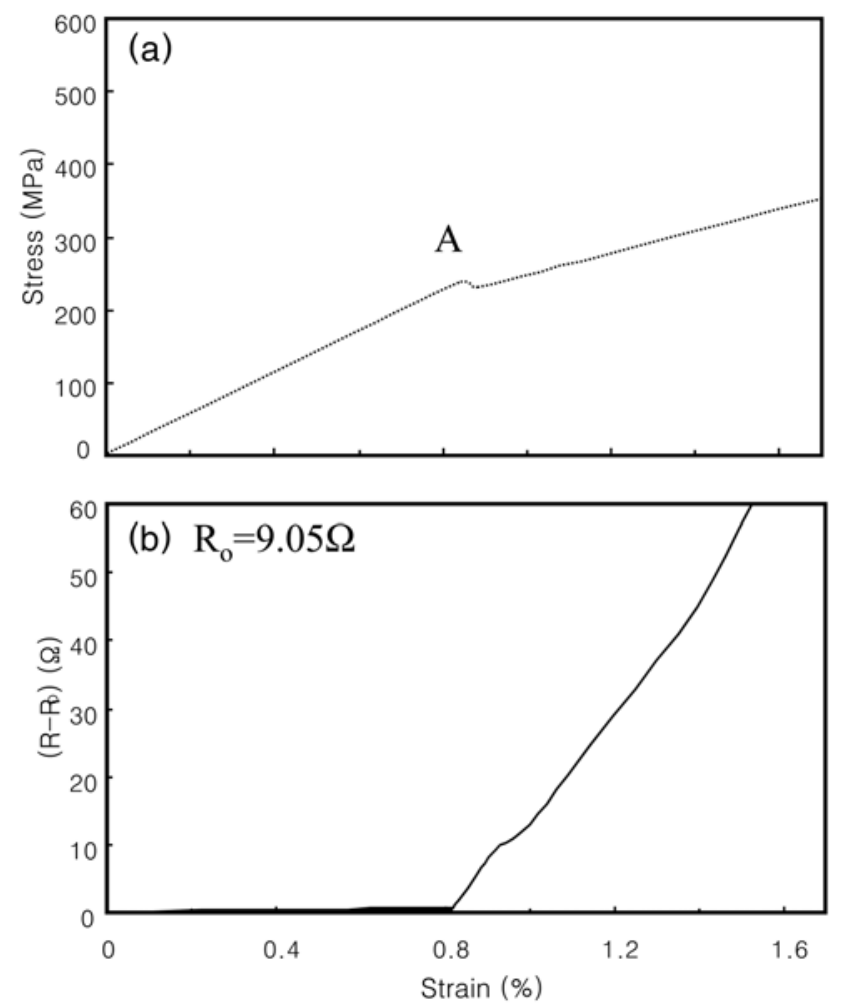

Fig. 4. Changes in stress (a) and electrical resistance (b) as a function of strain for CF-GFRP/GFRP composites containing 0.58 vol. \% carbon fiber.

electrical resistance were measured by changing in electrical voltage with a constant current method of d.c. two-terminal method (powder source: ADVANTEST Co. Ltd, Japan: C.V. /C.C. source R6142). The electrical current was kept constant at $0.01 \mathrm{~mA}$ for CP-GFRP/GFRP and $10 \mathrm{~mA}$ for CF-GFRP/GFRP because of the different values of electrical resistance for each specimen. Two sheets of strain gauge (KYOWA Electronic Instruments Co. Ltd, Japan: KFRP-2-120-C1-6), having a gauge ratio of 2.1 and a size of $2 \times 1.2 \mathrm{~mm}$, were bonded to both sides of the specimen, and the strain was measured by these strain gauges. The changes of load, strain and electrical voltage were recorded in computer by data logger (KEYENE Co. Ltd, Japan: NR-110).

\section{Results and Discussion}

Fig. 4 shows the change in electrical resistance (R$\mathrm{R}_{\mathrm{o}}$ ) and stress as a function of strain for CF-GFRP/ GFRP composites $\left(\mathrm{R}_{\mathrm{o}}: 9.05 \Omega\right)$ containing 0.58 vol. \% PAN-HMCF which is loaded singularly in tension. The stress increased almost linearly in proportion to strain until point A. A transition point in the strain/stress characteristics is observed around point $A$, which corresponds to the point where carbon fiber tows are broken while glass fiber tows still withstand the stress. This result
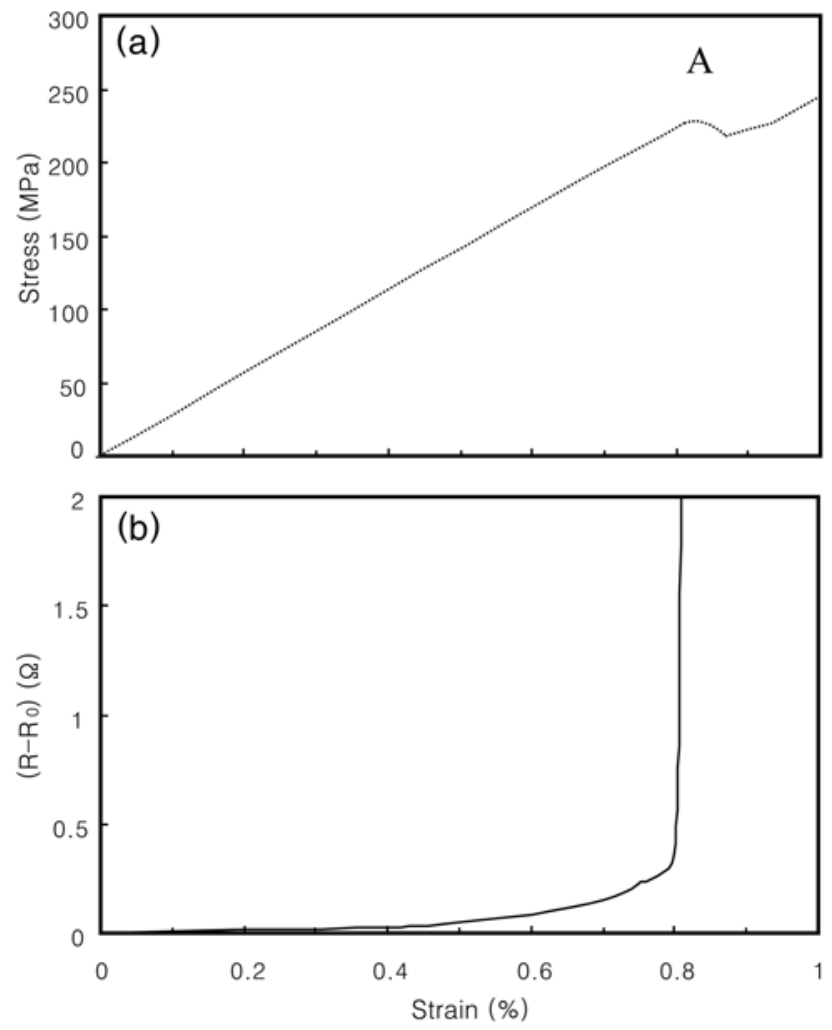

Fig. 5. Result of enlarged changes in stress (a) and electrical resistance (b) of Fig. 4.

shows that CF-GFRP/GFRP composites do not cut suddenly after the carbon fiber tows fracture. ${ }^{8)}$ The transition point A may be considered to be a signal indicating that further loading may lead to fatal fracture. However, the transition point of mechanical fracture at point A was vague, and the gradient of the curve did not change greatly at transition point A. The signal must be made much more distinctly.

In Fig. 4, a tremendous change in the electrical resistance of CF-GFRP/GFRP composites could be observed at the transition point A. Distinct changes in the electrical resistance occurred at the fracture of carbon fiber tows in the composites and afterwards the composites still withstand stress/strain because of the presence of glass fiber tows beyond the point of fracture of carbon fiber tows. The electrical signal was distinct compared to the mechanical signal. These distinct changes allow an easy check by monitoring changes in the electrical resistance for latent damage analyses of CF-GFRP/GFRP composites. The design for intelligent structural materials with a self-diagnosing function for preventing fatal fracture during loading is therefore to combine conductive fiber tows with a small value of elongation and insulating fiber tows with a large value of ultimate elongation.

Fig. 5 shows the result of enlarged changes in electrical resistance $\left(\mathrm{R}-\mathrm{R}_{\mathrm{o}}\right)$ of Fig. 4 for clarity. The changes in 

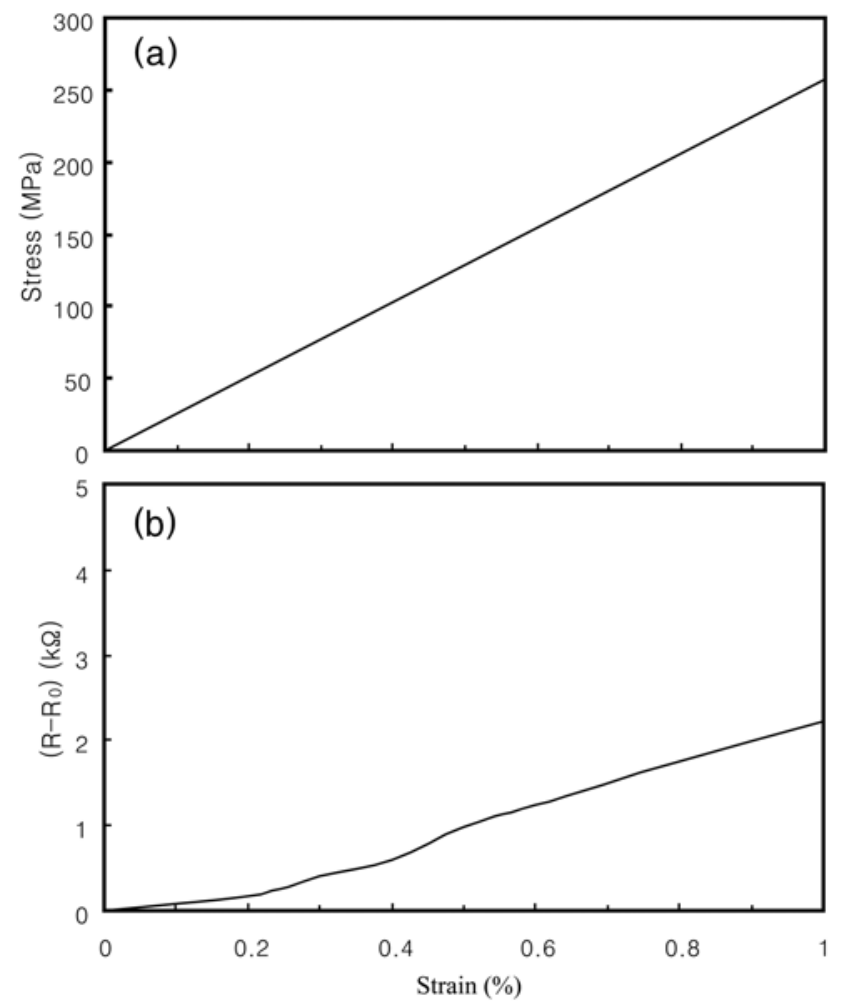

Fig. 6. Changes in stress (a) and electrical resistance (b) as a function of strain for CP-GFRP/GFRP composites containing 0.15 vol. \% carbon powders.

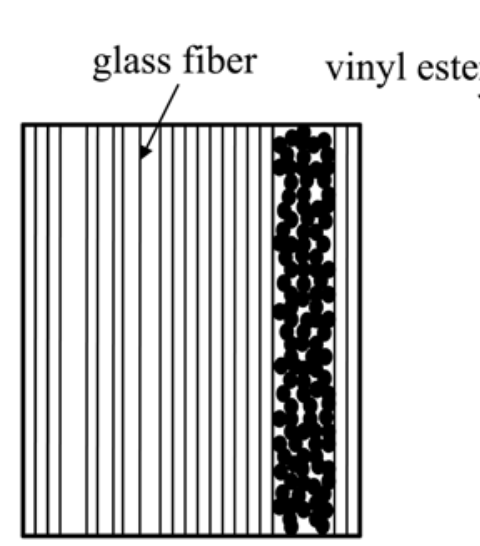

(a) carbon powder

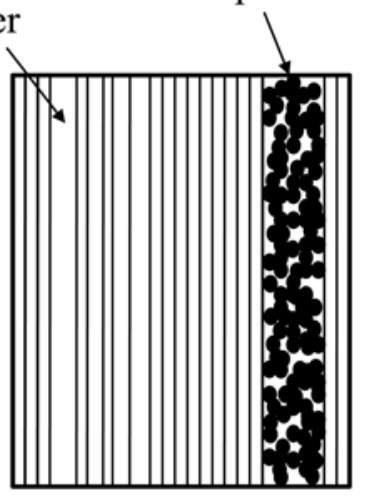

(b)
Fig. 7. Schematic drawing of (a) unloading and (b) loading state in CP-GFRP/GFRP composites.

electrical resistance of CF-GFRP/GFRP composites increased abruptly at $0.8 \%$ strain and the relative change in electrical resistance $\left(\mathrm{R}-\mathrm{R}_{\mathrm{o}}\right) / \mathrm{R}_{\mathrm{o}}$ for the strain was only $1.1 \%$ at $0.6 \%$ strain and $5.5 \%$ at $0.8 \%$ strain. The signal must be made much more distinctly for detecting damage from the early stages of damage. However, CFGFRP/GFRP composites are not able to monitor damage in principle by the change in electrical resistance from


Fig. 8. Changes in applied load (a) and electrical resistance (b) during bending test for CP-GFRP/GFRP composites embedded in a concrete specimen. The points $\mathrm{A}$ and $\mathrm{B}$ on the graph correspond to the photographs in Fig. 9.

the early stages of damage. So, it is necessary to develop new composites in order to detect damage from the early stages of damage.

Fig. 6 shows the change in electrical resistance $\left(R-R_{0}\right)$ and stress in as a function of strain for CP-GFRP/GFRP composite $\left(\mathrm{R}_{\mathrm{o}}: 9.08 \mathrm{k} \Omega\right)$ containing 0.15 vol. \% carbon powders. The stress and the changes in electrical resistance of the composites increased almost linearly in proportion to strain, and the relative change in electrical resistance $\left(\mathrm{R}-\mathrm{R}_{\mathrm{o}}\right) / \mathrm{R}_{\mathrm{o}}$ was $6.2 \%$ at $0.6 \%$ strain and $18.9 \%$ at $0.8 \%$ strain, respectively. These values were larger than those of CF-GFRP/GFRP composites, and these large changes allow an easy check by monitoring changes in the electrical resistance. Fig. 7 shows the schematic drawing of the unloading state and loading state in CPGFRP/GFRP composites, respectively. The large change in electrical resistance of CP-GFRP/GFRP composites may be considered to occur due to the phenomenon of percolation which occurs by movement of carbon powders from the contacted stage to the separated stage inside CP-GFRP rod with extending of GFRP rod surrounding CP-GFRP rod in tension. ${ }^{15-17)}$ The capability of damage monitoring by measuring changes in electrical resistance from the early stage of damage, CP-GFRP/GFRP composites are superior to CF-GFRP/GFRP composites.

Fig. 8 shows applied load and change of electrical resistance of CP-GFRP/GFRP composites as a function of displacement for the concrete specimen during bending. 


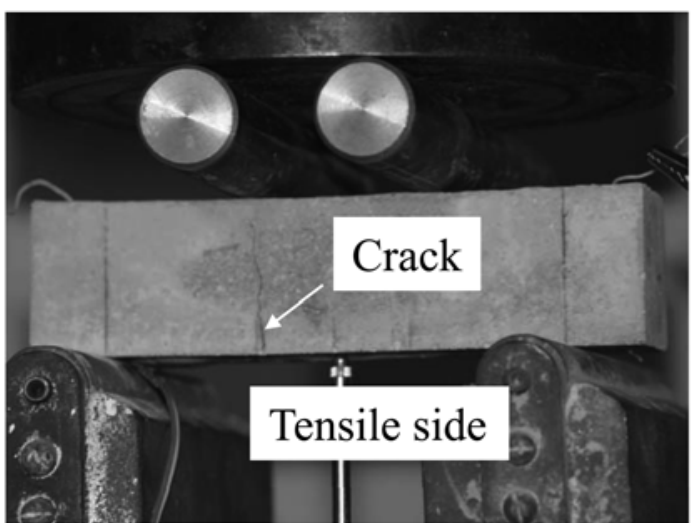

(a)



(b)

Fig. 9. Photographs of the concrete specimen at (a) point $\mathrm{A}$ and (b) point $\mathrm{B}$ of the bending test in Fig. 8 .

The load-displacement curve shows discontinuous changes at point $\mathrm{A}$ and $\mathrm{B}$, which correspond to crack formation and propagation in the specimen, respectively. Crack formation and propagation are visible in photographs of the specimen (Fig. 9). The electrical resistance of the composites increases gradually before crack formation. The increase in electrical resistance appeared simultaneously with micro-crack formation and discontinuous electrical resistance changes were also generated in response to cracks propagating through the matrix and fiber of the composites. The change of electrical resistance of embedded CP-GFRP/GFRP composites well corresponded with the increasing amount of damage inflicted on the concrete specimen. These results demonstrate that the embedded CP-GFRP/GFRP composites have the ability to monitor micro-crack formation/propagation of concrete structures.

\section{Conclusion}

CP-GFRP/GFRP composites with self-diagnosing function for preventing fatal fracture of concrete structures were studied and the following conclusions were obtained. The changes in electrical resistance of CF-GFRP/GFRP composites increased abruptly with increasing strain, and a tremendous change was observed at the transition point where carbon fiber tows were broken. Therefore, the composites are not to monitor damage from the early stage. On the other hand, the change in electrical resistance of CP-GFRP/GFRP composites increased almost linearly in proportion to strain. Also it was noted that the capability of monitoring by measuring change in electrical resistance from the early stage of damage, CP-GFRP/ GFRP composites used carbon powder is superior to CFGFRP/GFRP composites used carbon fiber. The selfdiagnosis ability of the CP-GFRP/GFRP composites en- abled the detection of micro-crack formation and propagation in concrete structures.

\section{Acknowledgement}

This work has been supported by the Campus Joint Research Program $\left(3^{\text {rd }}\right)$ in the year 2007 of Kangwon National University, Kangwon-do, Korea. The author would like to thank Dr. H. Matsubara and Mr. H. J. Lim for their technical assistance.

\section{References}

1. K. J. Konsztowicz and D. Fontaine, J. Am. Ceram. Soc., 731, 2809 (1990).

2. E. S. Leal and R. J. Lopes, Meas. Sci. \& Technol., 6, 188 (1995).

3. A. D. Kersey, in Proceedings of First World Conference on Structural Control (Los Angeles, CA, 1994), ed. H. Takagi, (Cmcbooks, Tokyo, 1994) p.167.

4. S. F. Masri, M. J. Devries and R. O. Clus, J. Eng. Mech., 120, 1696 (1994).

5. C. I. Merzbacher, A. D. Kersey and E. J. Friebele, Smart Mater. Struct., 5, 196 (1996).

6. K. Ikeue, Encyclopedia of Composite Materials, p.51, ed. H. Miyairi, Asakurasyoden, Tokyo (1991) (in Japanese).

7. K. Schulte and Ch. Baron, Compos. Sci. Technol., 36, 63 (1989).

8. N. Muto, H. Yanagida, T. Nakatsuji, M. Sugita and Y. Ohtsuka, J. Am. Ceram. Soc., 76, 875 (1993).

9. N. Muto, H. Yanagida, T. Nakatsuji, M. Sugita, Y. Ohtsuka and Y. Arai, Smart Mater. Struct., 1, 324 (1992).

10. N. Muto, H. Yanagida, T. Nakatsuji, M. Sugita, Y. Ohtsuka and Y. Arai, J. Ceram. Soc. Jpn., 100(12), 1429 (1992).

11. N. Muto, H. Yanagida, T. Nakatsuji, M. Sugita, Y. Ohtsuka and Y. Arai, Adv. Compos. Mater., 4(4), 297 
(1995).

12. Y. Arai, N. Muto, H. Yanagida, T. Nakatsuji, M. Sugita and Y. Ohtsuka, J. Ceram Soc., Jpn., 102(12), 745 (1994).

13. S. G. Shin, Met. Mater. Int., 7(6), 519 (2001).

14. Ishida. S, H. Yanagida, H. Matsubara and S. G. Shin, Japan patent; No. 9-207872, No. 11-220259.
15. D. Stauffer and A. Aharony, Introduction to Percolation Theory, $2^{\text {nd }}$ ed., Tayler \& Francis, London (1992).

16. S. G. Shin, H. J. Lim and J. H. Lee, Kor. J. Mater. Res., 13(11), 732 (2003).

17. S. G. Shin, Y. H. Kim and J. H. Lee, Kor. J. Mater. Res., 12(2), 135 (2002). 